\title{
Dissolution of fine Y' precipitates of MC2 Ni-based single-crystal superalloy in creep-fatigue regime
}

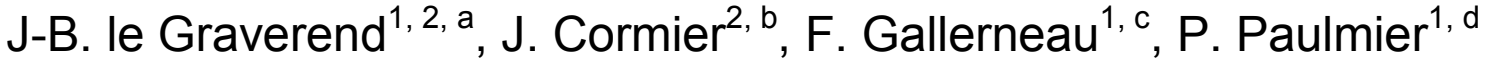

${ }^{1}$ Office National d'Etudes et de Recherches Aérospatiales, 29 avenue de la Division Leclerc, BP 72, 92322 Châtillon, France

${ }^{2}$ Institut Pprime CNRS-ENSMA-Université de Poitiers, UPR CNRS 3346, Département Physique et Mécanique des Matériaux, ENSMA, 1 avenue Clément Ader, BP 40109, 86961 Futuroscope

Chasseneuil Cedex, France

a jean-briac.le_graverend@onera.fr, ${ }^{b}$ jonathan.cormier@ensma.fr, ${ }^{c}$ franck.gallerneau@onera.fr, ${ }^{d}$ pascal.paulmier@onera.fr

Key words: Creep-fatigue, High temperature, Dissolution/Precipitation, Microstructure evolutions

\begin{abstract}
The dissolution kinetics of an ultra-fine $\gamma^{\prime}$ precipitation occurring in the $\gamma$ matrix between the standard secondary precipitates of MC2 Ni-based single crystal superalloy was investigated. Creep-fatigue experiments at $1050^{\circ} \mathrm{C}$ including an overheating at $1200^{\circ} \mathrm{C}$ were performed on $<111>$ oriented specimens to study the effects of fine $\gamma^{\prime}$ particles on the plastic deformation.

During these experiments, a decrease of the plastic deformation rate was observed just after the temperature peak.

This hardening effect disappears once the fine $\gamma^{\prime}$ precipitates had been dissolved. A mean time for this hyperfine precipitation dissolution could then be highlighted.

Based on both simple binary diffusion and complex diffusion analysis, the mean time for the dissolution of the fine $\gamma^{\prime}$ precipitates is analyzed and compared to the experimental ones. It is shown that considering only a simple binary diffusion is not sufficient and it should be considered a more complex diffusive analysis involving additional interplays.
\end{abstract}

\section{Introduction}

Ni-based single crystal superalloys have been widely studied under a wide range of isothermal creep conditions [1-2]. Besides this, during in-service operation of twin engine helicopters, one of the two engines may unusually stops. This implies a brutal rise up of the high pressure turbine blade temperature to around $1200^{\circ} \mathrm{C}$ for the remaining operating engine. Such an event is known as One Engine Inoperative (OEI) rating. Consequently, creep or creep-fatigue tests under isothermal conditions become insufficient to tackle the characterization of the mechanical properties under non-isothermal loading conditions described above. So far only few studies dealing with the mechanical testing under non-isothermal conditions have been conducted [3-5]. It was established from these studies that the $\gamma^{\prime}$ evolution is a significant creep controlling parameter. Besides, it is well admitted in the literature, that the major loss of the mechanical properties at very high temperature $\left(\mathrm{T}>1100^{\circ} \mathrm{C}\right)$ is directly linked to the dissolution of the strengthening $\gamma^{\prime}$ phase [1]. According to the above mentioned experiments, the temperature peak seems to be a crucial parameter in controlling mechanical tests at very high temperature conditions. Even more, simulation of the OEI ratings requires a special handling of the temperature control, particularly temperature levels and heating/cooling rates. In this context, this paper is devoted to the study of the effect of an overheating on creep-fatigue behaviour at very high temperature in relation with the $\gamma / \gamma^{\prime}$ evolutions, especially hyperfine $\gamma^{\prime}$ ones. 


\section{Experimental Procedure}

\section{Material}

The material considered here is MC2 single crystal, often classified as a non-rhenium containing second generation nickel base superalloy. Its microstructure consists of a large amount of refractory elements in addition to cobalt, chromium and aluminium: Table 1 gives its composition in weight percent. The as-received material was homogenized 3 hours at $1300^{\circ} \mathrm{C}$ then air quenched to dissolve all the $\gamma^{\prime}$ particles formed either by eutectic reaction during solidification or by precipitation during cooling. The material was then aged at $1100^{\circ} \mathrm{C}$ for $5 \mathrm{~h}$ and air quenched, and then at $870^{\circ} \mathrm{C}$ for $16 \mathrm{~h}$ followed by air quench. After the heat treatment, the strengthening $\gamma^{\prime}$ phase is cubic with an average precipitate edge length of $0.4 \mu \mathrm{m}$ and a volume fraction, $f_{\mathrm{v} \gamma}$, of $70 \%$ [6-7]. Specimens geometry was $14 \mathrm{~mm}$ in gauge length, $6 \mathrm{~mm}$ in width and $2 \mathrm{~mm}$ in thickness. Stress axis of the samples were close to a $<111>$ crystallographic orientation.

Table 1:

Composition of MC2 single crystal superalloy (in wt. \%).

\begin{tabular}{cccccccc}
\hline Ni & Cr & Co & Mo & W & Al & Ti & Ta \\
\hline balance & 8 & 5 & 2 & 8 & 5 & 1.5 & 6 \\
\hline
\end{tabular}

\section{Microstructure}

The microstructure analyses were carried out using Zeiss 962 and Zeiss 982 Gemini scanning electron microscopes operating at $25 \mathrm{kV}$. The samples were cut parallel and/or perpendicular to the loading axis and previously polished mechanically up to a mirror finish. The different scales of $\gamma^{\prime}$ precipitation were revealed by selective dissolution of the $\gamma^{\prime}$ phase using a triacid etching solution of $66 \% \mathrm{HCl}, 17 \% \mathrm{HNO}_{3}$ and $17 \% \mathrm{CH}_{3} \mathrm{COOH}$ at room temperature. The images processing were performed using Visilog ${ }^{\circledR}$ software which enhances the image features allowing better determination of the different precipitates size and their volume fraction [7].

\section{Mechanical testing}

Figure 1 shows the trapezoidal loading used for the creep-fatigue experiment at $1050^{\circ} \mathrm{C}$. The overheating is performed with no stress in different positions of the creep-fatigue life of the alloy. The main challenge to be achieved consists of reproducing in laboratory the brutal temperature rise up occurring during an overheating. Both the very high temperature and the heating and cooling rates during mechanical tests have to be well controlled to make sure that the experiments fulfil the one engine inoperative conditions [2]. To reach this goal, the induction heating was chosen and a Labview $^{\circledR}$ program was developed to control the currents generated by the inductor. The input signal waveform was chosen to allow monitoring the temperature accurately during the overheating. An additional proportional integral derivative loop was introduced to avoid any temperature overshoot during the simulation of the temperature jump which could induce dramatic effects on the mechanical response of the material [8].

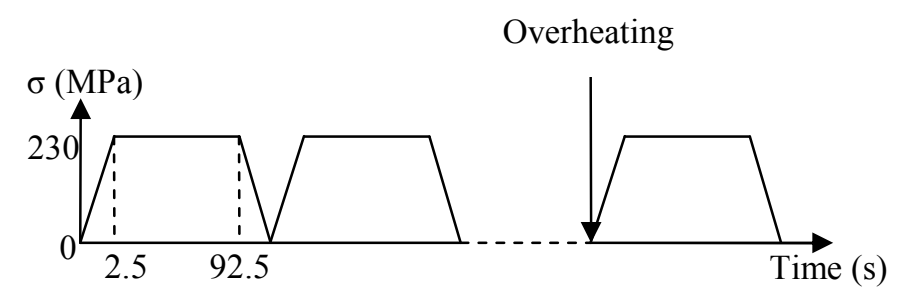

Fig. 1: Schematic illustrations of the mechanical loading during creep-fatigue experiments

An open inductor was used to allow strain measurements by using a contact extensometer. Additional details about those experiments can be found in [5]. 


\section{Results}

\section{Effect of one overheating on the as-received material}

A $180 \mathrm{~s}$ overheating was applied on the as-received material without any previous loading (test denoted in the following as 'Reference test'). The microstructure obtained after such thermal loading is given in Fig. 2. It is observed that $\gamma$ channels are wider than the ones observed on the asreceived initial microstructure. In addition, a fine $\gamma^{\prime}$ precipitation is localized in the widest $\gamma$ channels (see white arrows in Fig. 2a) while no fine $\gamma^{\prime}$ precipitates can be found in the thinnest ones. This observation is more clearly illustrated in Fig. $2 b$ (see black arrow). Therefore, it seems that a critical $\gamma$ channels width has to be reached to allow fine $\gamma^{\prime}$ precipitation. As mentioned elsewhere [9], in thin $\gamma$ channels, the finest $\gamma^{\prime}$ particles are too close to $\gamma / \gamma^{\prime}$ interfaces. Therefore, they coalesce back with attractive coarser precipitates. It is also observed intrusions in the remaining $\gamma^{\prime}$ coarse precipitates indicating that $\gamma^{\prime}$ dissolution occurs preferentially in these locations. This dissolution mechanism was already observed in MC2 alloy [8] and was attributed to dislocations/precipitates interactions. The main reason for such dissolution localization seems to be linked to the high stress levels in the matrix at the precipitates corners due to misfit stresses [10].
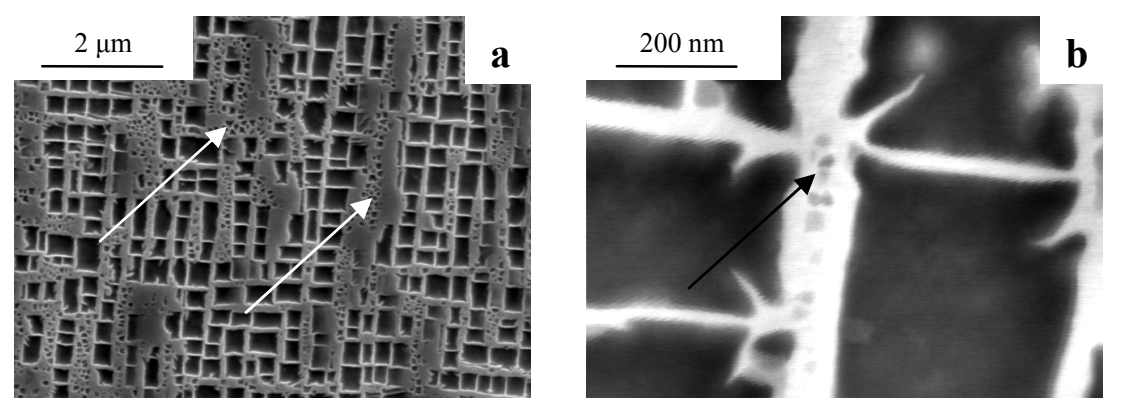

Fig. 2: Microstructure after a 180 s overheating: (a) general view with arrows indicating $\gamma$ channels where massive fine $\gamma^{\prime}$ precipitation (b) blow-up focusing on the $\gamma$ channels.

\section{Creep-fatigue tests including overheating}

Either one or two overheating(s) was (were) inserted in the creep-fatigue tests. For test 1, one overheating was introduced after 43 cycles (i.e. after $4085 \mathrm{~s}$ ) while for test 2, overheatings were introduced after 43 cycles and after 97 cycles (i.e. after 9215 s). The total strain evolution recorded during these tests and plotted as a function of time is presented in Fig. 3. A total deformation magnitude of $0.35 \%$ was induced by the first loading. Then, a progressive increase of the plastic deformation was observed cycle after cycle. The most striking result is that a plastic strain rate decrease is always observed just after an overheating. Afterwards, the strain rate progressively recovers a value close to the previous one reached before the overheating. The transient durations during which the plastic strain rate is reduced are highlighted in Fig. 3 by $\left(t_{1}-t_{\text {overheating } 1 .}\right)$ for test 1 and $\left(t_{1^{\prime}}-t_{\text {overheating1 }}\right)$ and $\left(t_{2}-t_{\text {overheating } 2 .}\right)$ for test 2 . Those durations are: $3800 \mathrm{~s}$ for the test 1,2000 and $3800 \mathrm{~s}$ for the test 2 . The difference in those durations after the first overheating between the two tests probably results from small microstructure differences (as-received $\gamma$ ' volume fraction or orientation) between the samples.

Fig. 4 illustrates the resulting microstructures after the $136^{\text {th }}$ and $177^{\text {th }}$ cycles (Fig. 4b and Fig. 4c), to be compared to the initial state given in Fig. 4a.

The microstructures exhibit the formation of fine $\gamma^{\prime}$ particles which have coalesced upon mechanical cycling after an overheating (see black arrows in Fig. 4c).

The next sections will emphasize the $\gamma^{\prime}$ precipitates kinetics of precipitation and dissolution. This will clarify the effect of these precipitates on the mechanical behaviour. 


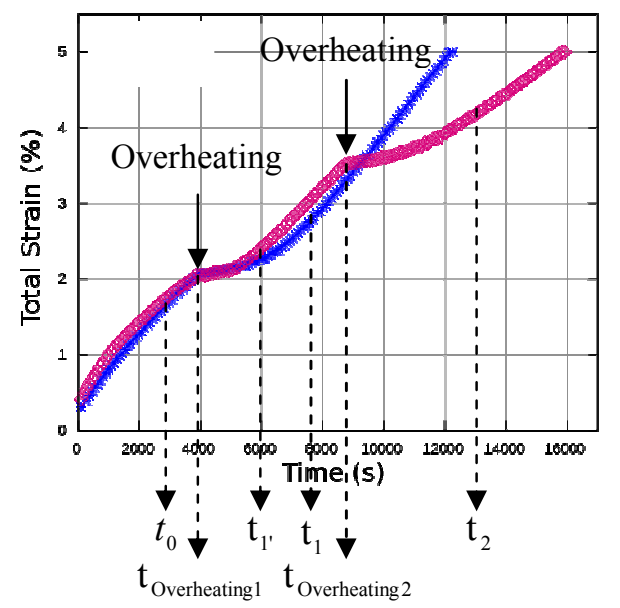

Fig. 3: Plastic strain evolutions during creep-fatigue experiments on $<111>$ oriented samples including either one or two overheating.
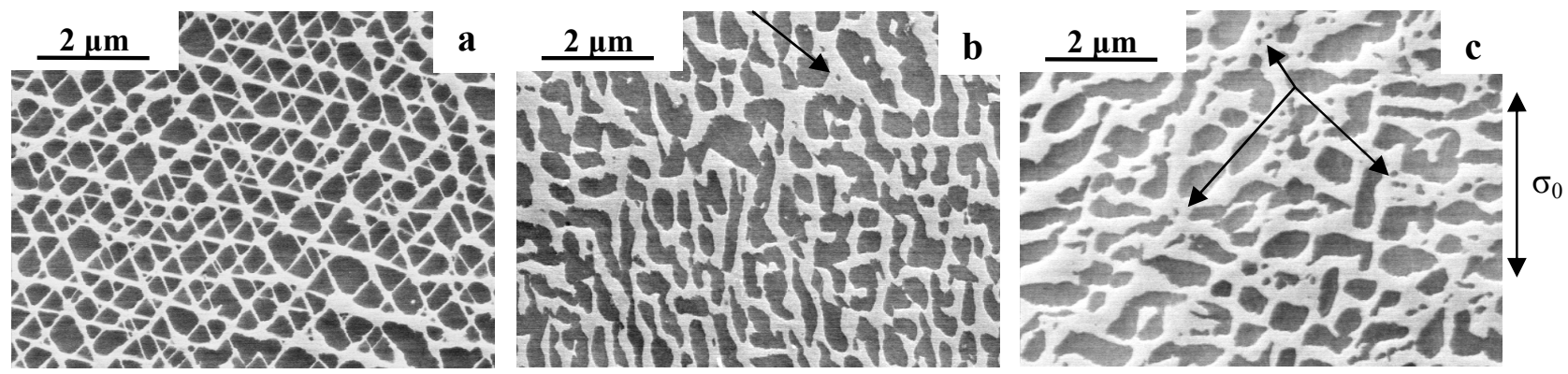

Fig. 4: Microstructures of $<111>$ oriented samples in the as-received conditions (a), at the end of creep-fatigue experiments including respectively one (b) and two (c) overheating(s). Black arrows in (b) and (c) indicate the presence of a fine precipitation in the $\gamma$ channels.

\section{Precipitation kinetics of $\gamma^{\prime}$ precipitates}

\section{Relationship between plastic strain and $\gamma$ ' precipitation}

An effect of the fine $\gamma^{\prime}$ precipitation on the material creep-fatigue behaviour is observed. Indeed, a higher volume fraction of the hyperfine particles is found at the end of the test 2 in comparison with test 1 (Table 2), leading to a lower total strain rate observed for the test 2 . The fine $\gamma^{\prime}$ volume fraction difference noticed between tests 1 and 2 does not result from the cycling durations after the last overheating experienced because the exposure times were equivalent for both tests ( 8835 seconds after the last overheating for test 1 and 7600 seconds after the last overheating for test 2). The reason could be found in the plastic strain level when the second overheating was performed in test 2 .

Table 2: Volume fraction of fine $\gamma^{\prime}$ at the end of experiments

\begin{tabular}{cccc} 
& Reference test & Test 1 & Test 2 \\
\hline Fine $\gamma^{\prime}$ volume fraction (\%) & 5.6 & 0.2 & 2.2 \\
\hline
\end{tabular}

Indeed it was higher than the one obtained just before the first overheating for both tests. Such a plastic strain difference may enhance $\gamma^{\prime}$ dissolution by pipe diffusion [11], as already mentioned elsewhere [3]. A higher volume fraction of fine $\gamma^{\prime}$ particles could hence be obtained on cooling from the second overheating. 


\section{Mean time determination of $\gamma^{\prime}$ precipitates dissolution}

The analyses of the microstructures obtained at the end of the non-isothermal creep-fatigue tests show a lower volume fraction of fine $\gamma^{\prime}$ precipitates compared to the volume fraction observed after the overheating performed on the as-received microstructure (see Table 2). This difference is due to the dissolution of these particles during subsequent mechanical testing after the overheating. Indeed, mechanical cycling after the overheating leads to a plasticity accumulation favoured by high temperature exposure $\left(1050^{\circ} \mathrm{C}\right)$, which enhances the dissolution of the fine $\gamma^{\prime}$ precipitates.

It is worth noticing that a bimodal $\gamma^{\prime}$ microstructure is considered to strengthen nickel base superalloys (by reducing the width of the $\gamma$ channels) as long as the fine $\gamma^{\prime}$ precipitates exist [3]. Therefore, it is interesting to characterize the fine $\gamma^{\prime}$ dissolution. A similar approach, based on the observed macroscopic fatigue behaviour, was already tackled by Cailletaud [12]. In our case, the observed hardening reduces the strain rate during $3800 \mathrm{~s}$ after the overheating for test 1 and during $2000 / 3800 \mathrm{~s}$ after the overheatings for test 2. Diffusive calculations were performed to estimate the time needed for the $\gamma^{\prime}$ precipitates to be dissolved by coalescence with the coarser precipitation. The Fick's second law was used and for sake of simplicity, we considered here a one dimension diffusion process. The resultant diffusion mean time $\tau$ in this case is typical of Brownian movement in one dimension, $d$ being the diffusion mean length and $D_{i}$ the diffusion coefficient of the element i (unit in $\mathrm{m}^{2} / \mathrm{s}$ ):

$$
\tau=\frac{\mathrm{d}^{2}}{2 \mathrm{D}_{\mathrm{i}}(\mathrm{T})} \text {. }
$$

As reported by Karunaratne et al [13], the diffusion coefficient, considering nickel solid solution, is given in Eq. (2) where $\mathrm{D}_{\mathrm{i}}^{\mathrm{Ni}}$ is the diffusion coefficient of the element $\mathrm{i}$ in pure nickel, $\Delta \mathrm{G}_{\mathrm{i}}^{\mathrm{Ni}}$ is the variation of the free enthalpy of the element $\mathrm{i}$ in pure nickel $(\mathrm{J} / \mathrm{mol})$ and $\mathrm{R}$ is the perfect gas constant.

$$
\mathrm{D}_{\mathrm{i}}^{\mathrm{Ni}}(\mathrm{T})=\exp \left(\frac{\Delta \mathrm{G}_{\mathrm{i}}^{\mathrm{Ni}}}{\mathrm{RT}}\right)
$$

According to [13], the variation of the free enthalpy of $\gamma^{\prime}$ former elements are given in the following:

$$
\begin{aligned}
& \Delta \mathrm{G}_{\mathrm{Al}}^{\mathrm{Ni}}=-14200+\mathrm{RT} \ln \left(1.71 \times 10^{-4}\right) . \\
& \Delta \mathrm{G}_{\mathrm{Ti}}^{\mathrm{Ni}}=-269267.07-68.81 \cdot \mathrm{T} . \\
& \Delta \mathrm{G}_{\mathrm{Ta}}^{\mathrm{Ni}}=-226313-109.20 \cdot \mathrm{T} .
\end{aligned}
$$

The calculations of the dissolution mean time $\tau$ were based on the slower diffusing element, for instance, tantalum for the studied temperature $\left(\mathrm{D}_{\mathrm{Ta}}^{\mathrm{Ni}}=2.310^{-15} \mathrm{~m}^{2} \cdot \mathrm{s}^{-1}\right)$. We also considered that $\gamma^{\prime}$ volume fraction is constant. Besides, in order to maximize the diffusion time constant, we considered the widest $\gamma$ channels at $1050^{\circ} \mathrm{C}$ which was determined to be about $5.610^{-7} \mathrm{~m}$ (determined after a creep-fatigue test in the same conditions which has been performed on a $<001>$ oriented sample - not shown in this article). Thus, the diffusing element has to browse half of the matrix channel width which was determined to be about $2.810^{-7} \mathrm{~m}$ by image analysis on the rafted microstructure. The obtained mean time is $17.0 \mathrm{~s}$.

This value is not representative of the diffusion time deduced from our experiments. Therefore, additional diffusion coefficient corrections have to be considered, as reported by Matan et al. [14]. Instead of considering only the diffusion in standard nickel solid solution, we have to take into account the diffusion in a complex structure such as $\gamma / \gamma^{\prime}$ superalloy. So, the new diffusion coefficient of nickel in the $\gamma^{\prime}$ phase is:

$$
\mathrm{D}_{\mathrm{Ni}}^{\gamma^{\prime}}=1.9 \cdot 10^{-4} \exp \left(\frac{-295 \cdot 10^{3}}{\mathrm{RT}}\right) .
$$


As given by [14] we have:

$$
\mathrm{D}_{\mathrm{Al}}^{\gamma^{\prime}}=\mathrm{D}_{\mathrm{Ti}}^{\gamma^{\prime}}=\frac{\mathrm{D}_{\mathrm{Ni}}^{\gamma^{\prime}}}{30} \text {. }
$$

The obtained mean time after corrections is $2741 \mathrm{~s}$.

The mean times reported above are in agreement with our experiments. For instance, $2741 \mathrm{~s}$ at $1050^{\circ} \mathrm{C}$ as mean time for creep-fatigue tests definitely corresponds to the hardening induced by the fine $\gamma^{\prime}$ precipitates that lasts in between 2000 and $4000 \mathrm{~s}$.

Those calculations allow a good estimation of the dissolution times in a very complex experimental context, even if it should be admitted that the effect of plasticity on the mean time for hyperfine $\gamma^{\prime}$ particles dissolution is not taken in account. Work is under progress to capture this plasticity effect on $\gamma^{\prime}$ particles dissolution/precipitation kinetics using phase-field simulations.

\section{Conclusion}

Original creep-fatigue tests at very high temperature were implemented to fulfil the one engine inoperative (OEI) conditions. Temperature peaks, performed during these tests, led to a better understanding of the $\gamma^{\prime}$ precipitation effect on the creep-fatigue behaviour of $\langle 111>$ oriented MC2 samples. For instance, a decrease of strain rate was observed after an overheating has been performed in the creep-fatigue life of the alloy. The strain rate decrease results from the precipitation of fine $\gamma^{\prime}$ particles in the $\gamma$ channels. This fine $\gamma^{\prime}$ hardening effect vanishes upon subsequent creep-fatigue cycling due to the progressive dissolution of those hyperfine precipitates. Calculations based on diffusion in a complex $\gamma / \gamma^{\prime}$ structure give a good approximation of the mean time for the hyperfine $\gamma^{\prime}$ particles dissolution.

\section{References}

[1] F. Diologent and P. Caron: Mat. Sci. Eng. A Vol. 385 (2004), p. 245-257.

[2] M. Kamaraj, C. Mayr, M. Kolbe and G. Eggeler: Scripta Mater. Vol. 38 (1998), p. 589-594.

[3] J. Cormier, X. Milhet and J. Mendez: Acta Mater. Vol. 55 (2007), p. 6250-6259.

[4] A. Raffaitin, D. Monceau, F. Crabos and E. Andrieu: Scripta Mater. Vol. 56 (2007), p. 277280.

[5] J.-B. le Graverend, J. Cormier, M. Jouiad, F. Gallerneau, P. Paulmier and F. Hamon: Mater. Sci. Eng. A Vol. 527 (2010), p. 5295-5302.

[6] B. Roebuck, D. Cox and R. Reed: Scripta Mater. Vol. 44 (2001), p. 917-921.

[7] J. Cormier, X. Mihlet and J. Mendez: J. Mat. Sci. Vol. 42 (2007), p. 7780-7786.

[8] J. Cormier, X. Milhet, J-L. Champion and J. Mendez: Adv. Eng. Mat. Vol. 10 (2008), p. 56-61.

[9] G. Boussinot: PhD Thesis, Université Pierre et Marie Curie, Paris, France, 2007.

[10] M. Probst-Hein, A. Dlouhy and G. Eggeler: Acta Mater. Vol. 47 (1999), p. 2497-2510.

[11] J.D. Embury, A. Deschamps, Y. Brechet: Scripta Mater. Vol. 49 (2003), p. 927-932.

[12] G. Cailletaud: PhD Thesis, Université Pierre et Marie Curie, Paris, France, 1979.

[13] M.S.A. Karunaratne, D.C. Cox, P. Carter and R.C. Reed in: the $9^{\text {th }}$ International Conference on Superalloys, edited by T.M. Pollock et al. TMS, Seven Springs, Champion, PA, USA, 2000, p. 263-272.

[14] N. Matan, H.M.A. Winand, P. Carter, M. Karunaratne, P.D. Bogdanoff and R.C. Reed: Acta. Mater. Vol. 46 (1998), p. 4587-4600. 